\title{
Interoceptive awareness and beliefs about health and the body as predictors of the intensity of emotions experienced at the beginning of the pandemic.
}

\author{
Aleksandra Modzelewska ${ }^{\text {Corresp., } 1}$, Kamil K. Imbir ${ }^{1}$ \\ ${ }^{1}$ Faculty of Psychology, University of Warsaw, Warsaw, Masovian, Poland \\ Corresponding Author: Aleksandra Modzelewska \\ Email address: a.modzelewska4@uw.edu.pl
}

Background. The COVID-19 pandemic is a type of stressful event which might impact on psychological state. A prolonged threat of getting a serious, contagious illness is expected to be associated with an increase of negative emotions and conversely, with a decrease of positive emotions. As the stressor is strongly linked to health and the body, we decided to investigate what types of factors related to body perception and appraisal are associated with different types of reported emotions. The purpose of the study was to verify the associations between three types of variables: interoceptive awareness as described by Mehling and colleagues $(2012 a, 2018)$, negative beliefs about health and body, and different types of emotions.

Methodology. A Multidimensional Assessment of Interoceptive Awareness questionnaire was applied to evaluate interoceptive awareness. The declared emotional state was diagnosed with a list of twenty emotions - divided by valence and origin. Additionally, a list of ten negative beliefs about health and body was used. The study was held in a correlational schema with 299 subjects recruited via the social media platform Facebook who took part in an online survey.

Results. The study revealed that the scales of Self-Regulation and Trusting are primarily associated with negative automatic and reflective emotions and positive automatic emotions. Furthermore, the SelfRegulation, Trusting dimensions of interoceptive awareness predict an intensity of emotions categorised on the basis of valence and origin. In addition, negative beliefs about health and the body provided an adequate explanation of the variance of most of the types of emotions experienced during the pandemic.

Conclusions. Factors related to body perception, such as interoceptive awareness and negative beliefs about health and body provide a significant contribution to explaining emotional state at the beginning of the pandemic. 
1 Interoceptive awareness and beliefs about health and

2 the body as predictors of the intensity of emotions experienced at the beginning of the pandemic.

Corresponding Author:

Aleksandra Modzelewska

Faculty of Psychology, University of Warsaw

Stawki 5/7, Warsaw, Masovian district, 00-183, Poland

Email address: a.modzelewska4@uw.edu.pl

\section{Abstract}

Background. The COVID-19 pandemic is a type of stressful event which might impact on psychological state. A prolonged threat of getting a serious, contagious illness is expected to be associated with an increase of negative emotions and conversely, with a decrease of positive emotions. As the stressor is strongly linked to health and the body, we decided to investigate what types of factors related to body perception and appraisal are associated with different types of reported emotions. The purpose of the study was to verify the associations between three types of variables: interoceptive awareness as described by Mehling and colleagues (2012a, 2018), negative beliefs about health and body, and different types of emotions.

Methodology. A Multidimensional Assessment of Interoceptive Awareness questionnaire was applied to evaluate interoceptive awareness. The declared emotional state was diagnosed with a list of twenty emotions - divided by valence and origin. Additionally, a list of ten negative beliefs about health and body was used. The study was held in a correlational schema with 299 subjects recruited via the social media platform Facebook who took part in an online survey.

Results. The study revealed that the scales of Self-Regulation and Trusting are primarily associated with negative automatic and reflective emotions and positive automatic emotions. Furthermore, the Self-Regulation, Trusting dimensions of interoceptive awareness predict an intensity of emotions categorised on the basis of valence and origin. In addition, negative beliefs about health and the body provided an adequate explanation of the variance of most of the types of emotions experienced during the pandemic.

Conclusions. Factors related to body perception, such as interoceptive awareness and negative beliefs about health and body provide a significant contribution to explaining emotional state at the beginning of the pandemic. 
41

42

43

44

\section{Introduction}

\subsection{The ecological background of the study - the context of the pandemic}

This study was run during the beginning of the COVID-19 pandemic in Poland, from 27 March until 15 April 2020. The severity of the pandemic at that time can be described by the following indicators: on 27 March 1389 cases of COVID-19 had been diagnosed and 16 patients had died, whereas on 15 April, 7582 cases were diagnosed, there had been 286 fatalities and 668 had recovered. During that period, the government implemented many restrictions limiting ordinary social activities. From 1 April, the government announced a ban on movement to reduce the rate of spread of the epidemic. The "lockdown" strategy was used for the first time in Poland. It can be said that the study was conducted during a period of significant restrictions on civil liberties and a serious growth of the pandemic; additionally, the novelty of the situation could have provoked increased stress. A pandemic is a stressful event, which significantly influences individuals' emotional states.

In the current study, we would like to focus on the subject's declared emotional state during the first stage of the pandemic, and to verify the factors that may modify this state. Interoceptive awareness is related to emotional experience (e.g., Barrett et al., 2004; Hanley et al., 2017), and therefore it should modify emotional reactions to threatening circumstances. At the same time, exposure to a serious, contagious disease involves a fear for one's health (Person et al., 2004). Accordingly, beliefs about health and the body were also included in the study design as a factor influencing emotional state during the first stage of the COVID-19 pandemic.

The pandemic situation can be highly stressful. Folkman and Lazarus (1985) defined stress as a type of relationship between humans and the environment when resources are exceeded. An individual experiencing an overloading situation might feel the threat of potential harm or loss, which is a stress component (Folkman \& Lazarus 1985). It is the perception of the situation in terms of a threat, not a challenge, that causes a negative emotional response (Dienstbier, 1989). Importantly, research demonstrated that threat perception is associated with cardiac and vascular reactivity (Tomaka et al., 1993). This is not the only manifestation of stress at the physiological level. The meta-analysis conducted by Dickerson and Kemeny (2004) revealed that acute psychological stressors are related to an increase in cortisol level; however, the reaction varied across conditions. In addition, stress also has a significant impact on mental health. Several meta-analyses confirmed the association between stress and depression (e.g., Kessler, 1997; Mazure, 1998; Monroe \& Hadjiyannakis, 2002; Paykel, 2003). Essentially, there is evidence confirming the linear connection between the severity and amount of stressful events and vulnerability to depression (Kendler et al., 1998).

Data on the current pandemic confirm that people presently experience more stress than before. Research done in January and February 2020 in China confirmed that 54\% of respondents perceived the psychological impact of disruption caused by the COVID-19 pandemic as severe or moderate, $29 \%$ declared experiencing moderate or serious anxiety symptoms and $17 \%$ indicated a depressive reaction (Cullen et al., 2020). If we look at data describing past epidemics, we can conclude that this type of phenomenon is inherently a large emotional burden. In a paper about the psychological consequences of the influenza pandemic, Perrin (2009) indicated that although 
82 people do indeed address fear and new, unknown health dangers, the severity of anxiety

83 experienced and the type of coping strategies are determined by individual differences and might

84 evolve during the epidemic. There are many examples in the empirical literature illustrating the

85 influence of epidemics on mental health and emotional state. For example, during an outbreak of

86 Legionnaires Disease in Japan, 17.6\% of respondents reported feeling stressed, 13.7\% reported

87 anxiety and insomnia and 3.3\% reported severe depression. Moreover, 3-4 months after the

88 breakout, some patients still demonstrated mental health problems (Tsuruta, et al., 2005).

89 Similarly, in $18 \%$ of the study population, severe acute respiratory syndrome (SARS) in Hong

90

91

92

93

94

95

96

97

98

99

100

101

102

103

104

105

106

107

108

109

110

111

112

113

114

115

116

117

118

119

120

121

122

123
Kong was associated with anxiety, post-traumatic stress disorder and depression symptoms (Wu et al., 2005). Taking into account the above empirical data, it can be seen that a pandemic is associated with various emotions and might cause a distress response with serious consequences for mental health. So, the question is, what kind of emotions are presently people experiencing, during the COVID-19 pandemic? To answer this question, we first need to define appropriate dimensions to describe emotions.

\subsection{Types of emotions - valence and origin components}

To discuss the nature of the dimensions of emotion, it is first necessary to briefly define the concept of emotion. Some authors define emotions as a response (physiological, psychological and behavioural) (Frijda, 2007) to the evaluation of stimuli (Jarymowicz \& Imbir, 2015)which might address both biological aspects (Damasio, 2010) and the cognitive interpretation of the ongoing situation from the perspective of an individual's goals and standards (Clore \& Ortony, 2010). Consecutively, Moors and Fischer (2019) consider emotions as a product of a goal-directed mechanism, referring to adaptability. Emotions express a tendency to action directed towards the achievement of a goal. The appraisal theories of emotions emphasise the relevance of the stimulus in reference to goals (Moors et al., 2013). The appraisal of stimulus is a type of verification of the congruence of stimulus with goals and controllability of this goal, thus it influences behaviour. The proposed view on emotions is in line with an alternative approach to dual-processes in the action and emotion domain proposed by Moors, Boddez and De Houwer ( 2017). The goal-oriented processes are considered a default (instead of stimuli-driven); moreover, these processes are not limited to the regulation of emotion, but are expected to strongly affect the formulation of action tendencies. The goal-oriented approach emphasises the role of possible control of aversive stimuli - when an individual is facing a choice between a fight or flight reaction, the choice is dependent on the expected utility of both reactions (Moors et al., 2019).

Taking into account the multitude of definitions and the variety of approaches (sometimes partially or completely contradictory to each other), one can get the impression that the construct of emotions still arouses some controversy, and the outlining of an unambiguous definition accepted by most researchers seems to be instinctive, albeit difficult to achieve.

To get deeper into the concept of emotions it is useful to address the key dimensions of this phenomenon. One of the basic dimensions of emotions is valence, a factor defined as the pleasantness or unpleasantness of experiences (Barrett, 1998; Lazarus, 1991). Valence results from appraisal the of stimuli as positive, negative or neutral, thus reflecting the basic biological 
124

125

126

127

128

129

130

131

132

133

134

135

136

137

138

139

140

141

142

143

144

145

146

147

148

149

150

151

152

153

154

155

156

157

158

159

160

161

162

163

164

165 tendency of approaching and avoiding. This elementary dimension enables the description of the emotional state in terms of positive and negative emotions, thus responding to the basis of the need to define feelings experienced in terms of comfort and discomfort. It is common to both the theoretical scientific approach and the common typology of emotions.

While the dimension of valence is fundamental in most research on emotion, there are still limited data about the origin dimension. This dimension refers to the broader heart-mind dichotomy rooted in classical philosophy. Based on the origin typology proposed by Jarymowicz and Imbir (2015), emotions can be divided into those resulting from automatic ("heart”) evaluative processes that do not need explicit cognition to appear and those following reflective ("mind") evaluative processes that are based on extended cognition (Jarymowicz \& Imbir, 2015). Automatic emotions result from internal drives and needs; they also refer to external incentives that play a crucial role in social and physical survival. They are thus related to the concept of biological value (Damasio, 2010), an automatic criterion of evaluation that gives an organism the sense of what is good for survival (i.e. pleasant) or bad (i.e. unpleasant). Automatic emotions are regulated by affect (Zajonc, 1980)) and thus have a diffusive, holistic and homogeneous character (Jarymowicz \& Imbir, 2015). The automaticity and reflectiveness in this approach are related to different degrees of cognition; automatic emotions need a minimal level of cognition to occur, in contrast to reflective ones. Nevertheless, the automaticity is not understood synonymously as absolute spontaneity. Reflective emotions are driven by intellectual, "mind” principles; their evaluation has a verbalised nature (Reykowski, 1989; Strack \& Deutsch, 2004, 2014). They are relatively heterogeneous and precise. The criteria of evaluation develop over the entire lifespan and are based on reflections concerning what is good or bad (Jarymowicz, 2012; Jarymowicz \& Imbir, 2015).

The proposed theoretical conceptualisation of automaticity and reflectiveness in terms of emotion deliver an interesting framework; however, its postulates might draw some contraventions. For example, Moors and De Houwer (2006) question defining a concept of automaticity through categories such as unintentionality, uncontrollability, autonomy, stimulus dependency, goal independence, efficiency and high speed. Researchers indicate the overlapping character of these components and suggest investigating each feature separately. Moreover, based on theoretical analysis, authors conclude that the features mentioned have rather a dimensional nature, therefore cognitive and emotional processes should be located somewhere on a continuum.

Nevertheless, in the current study we used Jarymowicz and Imbir's (2015) view on emotions, treating automaticity and reflectiveness as opposite ends of a scale representing the engagement of explicit deliberation towards stimulation, leading to interpretation of the situation. In our opinion, this approach might offer a promising theoretical framework to investigate the possible diversity of emotions reported during the pandemic.

\subsection{Factors related to psychological attitude towards the body affecting emotional state}

In the context of the pandemic, stress, which is naturally experienced within the body, seems to be strongly associated with concern about the condition of one's body, in other words, about one's health. Therefore, we might assume that an individual's perception and awareness of 
166 their body might influence their currently self-reported emotional state. One such factor might be 167 cognitive beliefs about the body resulting from perception and evaluation of the body. A Health 168 Beliefs Model delivers a kind of theoretical support for the importance of individuals' beliefs, 169 health and behaviour (Hochbaum, 1985; Rosenstock, 1966; 1960; Rosenstock et al., 1988). This

170 model was initially designed to explain the failures of prevention programmes relating to health , and then it was expanded to explain reactions to symptoms and diagnosed diseases. The model refers to value-expectancy theory and includes the perceived severity of illness, the perceived benefits, or action taken to reduce the threat of illness and promote health and perceived barriers referring to cost-benefit analysis if the actions taken involved any sacrifices (Rosenstock, Strecher \& Becker, 1994). The role of beliefs in the approach to disease conceptualised in the model was empirically verified (see, for example, the meta-analysis conducted by Harrison, Mullen and Green (1992)). Furthermore, research proved that optimistic self-beliefs enhance health-protecting behaviour through setting goals, taking actions and building motivations (Schwarzer, 1994). Finally, the relationship between emotional state and beliefs can be addressed with the ABC model constituting one of the foundations in CBT and RET therapies. Based on the model, cognition mediates emotional reaction (Ellis, 1991).

By describing how people experience their bodies, a distinction can be made between the perceived sensations and the declared state. When a person suffers from the disease, the observed physiological dysfunctions are associated with symptoms reported by this person (Pezzulo et al., 2019). However, some fluctuations in this relationship can be noticed. To explain why the relationship between objective disease parameters and symptoms reported by patients may vary significantly, Pezzulo and colleagues (2019) proposed a new predictive processing coding perspective. In this conceptualization, the experience of symptoms is the product of not only interoceptive perception but also predictions of the brain about detected interoceptive signals. We can therefore conclude that the perception process is not independent of the previously encoded meanings. Apart from perception (defined as predictive coding), the model also includes the level of action understood as an active interference. The role of pre-existing (prior) information in the construction of newly occurring representation expresses some similarity to the influence of cognitive beliefs on the formulation of emotional response.

To discuss further the role of related factors in shaping emotional state, we going to describe the concept of interoceptive awareness. The interoception is currently one of the major topics in mental health and body-mind based interventions ( Mehling et al., 2018). Recent approaches put a strong emphasis on the beneficial influence of the enhancement of body awareness, especially in individuals who are professionally involved in mind-body therapies like yoga, tai chi or meditation (Mehling et al., 2009, 2012, 2011). Moreover, some indicate that an increase of interoceptive awareness observed in mindful awareness in body-oriented therapy (MABT) has a beneficial influence on an individuals' emotional state. It supports the ability to adequately detect and classify physiological sensations, therefore it enables an adequate reaction to stressful stimuli and appropriate regulation (Price \& Hooven, 2018). Considering the literature cited, we drew a conclusion that interoceptive awareness should play a crucial role in explaining the emotions experienced. For a broader discussion of the topic of interoceptive awareness, some 
207

208

209

210

211

212

213

214

215

216

217

218

219

220

221

222

223

224

225

226

227

228

229

230

231

232

233

234

235

236

237

238

239

240

241

242

243

244

245

246

247

248 definitions will first be presented, and then the relationship between interoceptive awareness and emotions will be described.

Interoception can be defined as a process reflected in nervous system activity by which signals both from and within the body are detected, interpreted and integrated (Mehling et al., 2018), and which is also understood as a body-to-brain axis related to the state of the inner body and visceral organs (Cameron, 2001). Quadt and colleagues (2018) emphasise a basic function of interoception, which is keeping the body alive through the afferent channel of the brain and body interaction oriented to maintenance of homeostasis. Tsakiris and Critchley (2016) described interoception as a process of detecting and sensing internal states through the processing of inner body sensation. Considering the definition thus noted, it is worth emphasising, however, that awareness of the state of the inner body and visceral organs (Cameron, 2001) differs from detection, followed by interpretation and integration (W. E. Mehling et al., 2018). The understanding proposed by Mehling is a wider concept and seems to refer both to awareness of bodily psychological sensations and to the appraising interpretation occurring with such awareness (W. Mehling, 2016; W. E. Mehling et al., 2012a). This type of understanding corresponds with the four (4) dimensions of interoception theory, based on which, the following stages of interoception can be designated: occurrence of afferent signals (1); encoding, integration and generation of representation (2); influence on cognitive and behavioural processes (3), a conscious expression of representation of inner bodily signals (4) (Quadt et al., 2018a). Generally, people differ in terms of their ability to detect and properly report inner body signals. Thus, the question arises of how to assess interoceptive awareness? The concept of interoceptive awareness understood as an ability to detect, interpret and integrate inner bodily sensations is the foundation of the self-reported measurement tool, the Multidimensional Interoceptive Awareness Questionnaire developed by Mehling and coworkers (Mehling et al., 2018, 2012). The questionnaire was applied in the current study as it is enables individuals to make a selfdescription in terms of interoceptive awareness linked with emotions, consciousness and behaviour (Mehling et al., 2013). The tool is built of eight scales addressing such components of interoceptive awareness as: Noticing; Not-Distracting; Not-Worrying; Attention Regulation; Emotional Awareness; Self-Regulation; Body Listening; and Trusting. The use of self-reported measurements also has some limitations. Recent research indicates that people express a limited ability to accurately reason about their inner bodily states, such as current cardiac activity (Iodice et al., 2019).

A more detailed description of the questionnaire is provided in the Materials \& Methods section.

After the definitions of interoception have been outlined, we would like to discuss the relationship between interoceptive awareness and emotions. Firstly, the role of interoception understood in the narrow sense as a perception of the physiological circumstances of the body, will be discussed. Interoception is the basis of subjective emotional experience (Calì et al., 2015). Many theories of emotion accentuate the role of perception and interpretation of interoceptive signals (Damasio, 1994; Schachter \& Singer, 1962). The exploration of the relationship between emotions and interoception became a topic of frequent interest to researchers (Calì et al., 2015a). For instance, Damasio and colleagues emphasised the role of the representation of bodily experience in the brain, which is associated with specific emotions, subsequently affecting a 
249

250

251

252

253

254

255

256

257

258

259

260

261

262

263

264

265

266

267

268

269

270

271

272

273

274

275

276

277

278

279

280

281

282

283

284

285

286

287

288

289 decision making process (Damasio, 1998; 1994; Damasio et al., 2000). It was empirically demonstrated that individuals who are more sensitive interoceptively experience emotions more intensively (Montoya et al., 1993; Pollatos et al., 2005, 2007; Wiens et al., 2000). For example, research has shown that individuals highly aware of cardiac activity demonstrate a significantly stronger cardiac reaction to pleasant and unpleasant stimuli compared to less aware individuals (Pollatos \& Schandry, 2008). Interestingly, interoceptive awareness seems to be associated with perception and appraisal of the arousal dimension (seee.g.: Barrett et al., 2004; Dunn et al., 2010). Moreover, higher interoceptive awareness was associated with greater recognition of affectively stimulating pictures, which might prove that individuals characterised by higher interoceptive awareness process emotionally arousing materials in a more conscious way (Pollatos \& Schandry, 2008). Calì and colleagues suggested that interoception might influence emotional processing through a trait called emotional susceptibility, understood as a vulnerability and propensity to experience discomfort in response to emotionally charged stimuli (Calì et al., 2015). The proposed mechanism explaining the relationship between interoception and emotional experience seems to be supported by growing evidence of the role of the insula in interoceptive and emotional processes (e.g. Ernst et al., 2013; Zaki, Davis, \& Ochsner, 2012). Taking into account the data quoted, it is not surprising that, in psychopathology body awareness was initially linked with excessive attention towards bodily sensations (or even symptoms) resulting in somatisation, rumination and catastrophic beliefs (Cioffi, 1991).

When considering interoceptive awareness in the wide sense, it is worth mentioning the study by Calì and colleagues (2015) once again. Research revealed that of the dimensions of the MAIA questionnaire (Attention Regulation, Trusting, Not-Worrying and Emotional Awareness) predicting emotional susceptibility (Calì et al., 2015), only Emotional Awareness is positively correlated with emotional susceptibility, whereas the rest of the scales are negatively correlated. A mindful, accepting experience of bodily sensations is a fundamental aspect of embodiment (Carruthers, 2008; Fogel, 2009). Many studies have shown that there is a link between mindfulness and interoception (Farb et al., 2015; Hölzel et al., 2011; Mehling et al., 2012; Tang, Hölzel, \& Posner, 2015). In essence, both concepts can be theoretically and functionally treated as intertwined (Farb et al., 2015; Hölzel et al., 2011): mindfulness offers practices directly engaging interoceptive awareness and is based on the interoception mechanism as an intervention (Bornemann \& Singer, 2017; Farb et al., 2015; Hölzel et al., 2011). Research has revealed that both IA and dispositional mindfulness predict psychological well-being (Hanley et al., 2017).

Summing up the empirical data cited, the conclusion is that both beliefs about health and body and interoceptive awareness are associated with emotional experience. The relationship seems to be rather complex and further research in this area seems necessary.

\subsection{Aim and Hypothesis}

The current study seeks to address the understanding of the nature of the relationship between the types of variables: a self-reported emotional state classified on the valence and origin scales, dimensions of interoceptive awareness (Mehling et al., 2012a, 2018) and negative beliefs about health and body. 
290

291

292

293

294

295

296

297

298

299

300

301

302

303

304

305

306

307

308

309

310

311

312

313

314

315

316

317

318

319

320

321

322

323

324

325

326

327

328

329

330

331

At first, the investigation was narrowed down to dimensions of interoceptive awareness and all types of emotions: negative automatic and reflective, positive automatic and reflective.

Therefore, we predicted that there is an association between two sets of variables: (I) all types of emotions and (II) the level of interoceptive awareness (H1). To examine multivariate networks of association between interoceptive awareness and different types of emotions, a canonical correlation analysis was planned.

Secondly, the aim of the study was to verify the relationship between negative beliefs and the emotions experienced. We expected that negative beliefs are positively associated with negative automatic and negative reflective emotions (Neg. Aut. Emo.; Neg. Refl. Emo.) (H2a). By contrast, negative beliefs are predicted to be negatively related to both automatic and reflective positive emotions (H2b).

We predicted also that there is generally a negative association between the MAIA scales and negative beliefs (H3).

Finally, the aim of the study was to demonstrate multiple distinct associations between all variables investigated. Research indicates that interoception might predict the intensity of emotional experience (see e.g. Dunn et al., 2010; Pollatos et al., 2005; Terasawa et al., 2014). Analogically, taking into account the ABC Ellis (Ellis, 1991) model used in cognitive or REBT therapy, the type and intensity of emotions experienced can to some extent be explained by referring to the subjective beliefs of the individual. Accordingly, based on the current state of knowledge, we assumed that the direction of the relationship runs from negative beliefs and MAIA scales to emotions. In other words, both MAIA scales and Neg. beliefs were expected to predict the intensity of Neg. Aut. Emo, Neg Refl. Emo, Pos. Aut. Emo and Pos. Refl. Emo (H4).

\section{Materials \& Methods}

\subsection{Participants}

The participants were volunteers recruited from different types of Facebook groups: groups associating local communities such as the inhabitants of big cities (Warsaw, Cracow, Trójmiasto and others), smaller cities and villages (like Mińsk Mazowiecki, Legnica, Ząbki and others) and regions (for example, masovian voivodeship, lubelskie voivodeship, świętokrzyskie voivodeship); groups of different university students (for example, the University of Warsaw, Warsaw Medical University, the Economic University in Cracow); and groups dedicated to different hobbies, like sport, health, self-development and psychology (but not addressed to professional psychologists). Group selection was designed to maximise sample diversification and avoid testing only the student population.

All Facebook groups are public and open to new members; however, some of them require filling in an additional survey to join the group. Members of the groups were asked to fill in an online survey consisting of several tools. The data was collected from 27 March to 15 April. During that time, about 50 posts were published with announcements encouraging individuals to take part in the study. This resulted in the receipt of more than 300 fully completed surveys. There was no remuneration for participation in the study.

The survey was completed by 327 Polish adults. The criteria applied to prepare the dataset were to exclude the responses wherein time of completion of the whole set of questionnaires 
332

333

334

335

336

337

338

339

340

341

342

343

344

345

346

347

348

349

350

351

352

353

354

355

356

357

358

359

360

361

362

363

364

365

366

367

368

369

370

371

372

373

374 differed by more than two standard deviations from the mean $(M=7.92$ minutes; $S D=3.76$; the time range for completing the study was from 2.68 minutes to 28.13 minutes). Based on that, 28 subjects' responses were removed. The final participant number was $N=299$ (236 women, 62 men and 1 other), aged between 18 and 67 years old $(M=30.41$; $S D=10.96)$.

No personal data was collected that would allowing us to identify participants. The demographic characteristics of the sample are included in Appendix 1.

\subsection{Design}

The study was held in a correlational schema. There were three variables measured: (1) emotions experienced; (2) interoceptive awareness; and (3) negative beliefs about health and body.

\subsection{Materials}

\subsubsection{Types of emotions}

Several tools were applied to measure the variables that were investigated. The first was a measurement of the emotions that had been experienced, consisting of two scales, one referring to negative emotions and the other referring to positive emotions (each scale containing 10 items). A mean was calculated from each scale. The measurements describing emotional state also used the origin dimension, and therefore, means from four scales were also calculated (each scale containing 5 items). The list was created based on the distinction between automatic and reflective emotions (Imbir, 2016), and therefore, further analysis was based on the division of emotions not only by valence, but also by origin.

Participants were asked to rate to what extent they felt the emotion in question at that moment. A seven-point scale was used, on which 1 means "to a small extent" and 7 means "to a significant extent".

Among negative emotions, the automatic ones are: Suffering (Polish: Cierpienie); Helplessness (Bezradnośc); Frustration (Frustracja); Breakdown (Załamanie); and Terror (Przerażenie). Negative reflective emotions include: Shame (Wstyd); Sadness (Smutek); Dejection (Przygnębienie); Depression (Depresja); and Envy (Zawiść).

The positive emotions were divided into automatic ones as well: Alleviation (Ukojenie); Reassurance (Uspokojenie); Excitation (Ekscytacja); Relaxation (Odprężenie); and Tenderness (Czułość). The reflective emotions are: Persistence (Wytrwałośc); Compassion (Współczucie); Hope (Nadzieja); Courage (Odwaga); and Loyalty (Lojalność).

The choice of emotions had a theoretical and content-related character. Both the negative and positive emotions scales reached a good degree of reliability (negative emotions (Cronbach's alpha $=0.90)$; positive emotions (Cronbach's alpha $=0.77)$ ). Similarly, origin-based scales also reached a good reliability (negative automatic emotions (Cronbach's alpha $=0.85$ ); negative reflective emotions (Cronbach's alpha $=0.77$ ); positive automatic emotions (Cronbach's alpha = 0.74); positive reflective emotions (Cronbach's alpha $=0.65)$ ). The summary of emotion types is shown in Table 1. Means and standard deviations for emotion categories are shown in the summary Table 2.

--- Table 1 ---

--- Table 2 --- 
375

\subsubsection{Multidimensional Assessment of Interoceptive Awareness}

In the current study, the MAIA questionnaire was used. There are eight scales within the tool which correspond to an eight-factor structure. The following scales were distinguished: Noticing; Not-Distracting; Not-Worrying; Attention Regulation; Emotional Awareness; SelfRegulation; Body Listening; and Trusting. Each scale is built from 3-7 items. The internal consistency of subscales ranges from 0.66 to 0.87 , and inter-scale correlations range from 0.09 to 0.60 (Mehling et al., 2012). The current study used the Polish adaptation of the MAIA questionnaire (Mehling et al., 2012), developed by Anna Brytek-Matera and Anna Kozieł. The questionnaire scored very good reliability (Cronbach's alpha $=0.89$ ). The scales' reliabilities (Cronbach's alpha) achieved values from 0.59 to 0.89 . The results were compared with the reliability obtained in Mehling and colleagues' research (Mehling et al., 2012) and are shown in the summary Table 2 with means and standard deviations.

\subsubsection{Negative beliefs about health and the body}

The last tool applied in the current study was the list of negative beliefs about health and the body in the epidemic context. The scale was created for the purpose of this research to consider ongoing circumstances. To verify how people's ways of thinking about their health and bodies determine their emotional state, a list of ten negative beliefs was formulated. The list, alongside a translation, is included in Table 3. The statements refer to perceived threats to life and health and body resistance - including the perceived efficiency of respiratory and immune systems.

--- Table 3 ---

To verify if a set of beliefs creates a one factor scale, a confirmatory factor analysis was run. The factorial structure of the scale was verified with the use of confirmatory factor analysis based on the maximum likelihood method. A unidimensional structure of the scores was verified. The fit of the unidimensional model was adequate after allowing for additional correlations between consecutive items no. 1 and no. 2, $r=0.66, p<0.001$, items no. 6 and no. $7, r=0.38, p$ $<0.001$, items no. 9 and no. 10, $r=0.13, p<0.05$, as well as between items no. 8 and no. 10, $r=$ $0.20, p<0.001$, items no. 1 and no. $6, r=0.12, p<0.003$, and items no. 4 and no. $8, r=0.15, p<$ 0.05 . The values of fit indices were equal to $C F I=0.97, N F I=0.94, R M S E A=0.06$. Table 4 presents values of factor loadings acquired in the analysis.

The alpha reliability coefficient for the total scale was high and equal to 0.81 .

--- Table 4 ---

\subsection{Procedure}

The data was collected from 27 March to 15 April. The recruitment procedure consisted of publishing announcements encouraging individuals to take part in the study. The message contained information about the expected time needed to complete the survey, the general purpose of the study, information about the anonymous nature of the study and appeals encouraging people to participate in the study. The only excluding criterion was age: the study 
417 was only addressed to adult participants. No data that would allow us to identify participants was

418 collected during the study. The study was approved by Ethics Committee of the Faculty of

419 Psychology in the University of Warsaw.

420 The study consisted of informed consent to participate in the study and several

421 questionnaires, ordered as follows: measurement of emotions experienced; MAIA; beliefs about

422 health and body in relation to the ongoing epidemic; a demographic survey. The informed

423 consent included detailed information about who obtains the data and for what purpose,

424 information that the data is anonymously analysed for academic purposes only and that there are

425 no data permitting identification of the participants. Additionally, the consent contained a request

426 to fill out the questionnaires honestly and carefully, as there are no right or wrong answers. To

427 confirm consent to participate in the study, participants were asked to click the "Go further"

428 button. The consent was part of an online study; therefore it was given as an online approval, not

429 in writing.

430 The study was conducted via the Qualtrics platform. Each tool was displayed on a

431 separate screen. The first part was the assessment of emotional reaction. Participants were asked

432 to evaluate on a seven-degree Likert scale (where $1=$ not much, and $7=$ very much) how much

433 they currently experience each emotion. There were 20 emotions in total, all described above in

434 the section on tools. Then participants filled out the MAIA questionnaire.Afterwards,

435 participants were asked to assess how much they agree with the statements describing some

436 beliefs about health and the body in the epidemic context. There were ten statements for

437 assessment. The last part was the demographic survey. The following data were collected via this

438 survey: age, gender, place of residence, education and financial status (i.e. if someone has a

439 stable source of income and their perception of their financial status); state of health (i.e. if

440 someone suffers from a serious illness); and experiences related to the COVID-19 pandemic, like

441 knowing someone who has had the disease and having the virus oneself. The demographic survey

442 contained nine questions in total, most of which were closed.

\subsection{Statistical procedure}

The statistical approach was aimed at verifying the relationship between three sets of variables: interoceptive awareness measured with the MAIA questionnaire, a negative belief about health and body operationalised with ten statements and four types of emotions based on the valence-origin division. For this purpose, a canonical correlation analysis (CCA) was applied to examine the multivariate structure of the association between the components of interoceptive awareness and different types of emotions experienced (automatic negative emotions, reflective negative emotions, positive automatic emotions, reflective automatic emotions). To illustrate the relationship between all variables investigated, a path analysis was also run. This type of analysis enables one to build a model including various dependencies between variables.

Additionally, some preliminary analyses were performed, such as a t-Student comparison based on the demographic factors, correlation analysis and regression analysis.

\section{Results}


458

459

460

461

462

463

464

465

466

467

468

469

470

471

472

473

474

475

476

477

478

479

480

481

482

483

484

485

486

487

488

489

490

491

492

493

494

495

496

497

498

499

In the first step, the relationship between the demographic data and all types of emotions was verified. The results are included in the Appendix.

As a part of the preliminary analysis, a correlation analysis was performed for the following pairs of variables: all types of emotions and the MAIA scale, all types of emotions and negative beliefs about health and body, the MAIA scales. A summary of statistically significant results is attached in the Appendix file.

Additionally, a multiple block regression was run. The explanatory models were run separately for all types of emotions. Demographic variables, MAIA scales and negative beliefs about health and body were entered in separated blocks. A comparison of the predictors obtained in the final models is included in the Appendix file.

\subsection{Canonical correlations: the relationship between the MAIA scales and automatic and reflective emotions}

To investigate the multivariate shared association between two sets of variables - the components of the MAIA questionnaire and variables based on the valence and origin types of emotions - a canonical correlation analysis was conducted. The full model was statistically significant using Wilk's $\lambda=.63, F(32,1060.00)=4.41, p<0.001$., and explained $41 \%$ of the shared variance between the two sets of variables (see Figure 1). Four functions were investigated using squared canonical correlations corresponding to respectively: 1 ) Rc2 $=0.27,2$ ) Rc2 $=0.11$, 3) $\mathrm{Rc} 2=0.03$, 4) Rc2 $=0.01$. However, only two of them were statistically significant. The first $[27 \% ; F(31,1060)=4.41, p<0.001]$ and second $[11 \% ; F(21,827.53)=2.16, p=0.002)]$ functions explained a substantial portion of shared variance. In the first function, two scales of the MAIA questionnaire, Self-Regulation and Trusting, were principally associated with three types of emotions: Neg. Aut. Emo., Neg. Refl. Emo., Pos. Aut. Emo. The sign of the correlation index for the Self-Regulation and Trusting scales was positive, the same as the correlation index in the case of the Pos. Aut. Emo., and contrary to Neg. Aut. Emo and Neg. Refl. Emo. In the second function, two scales of the MAIA questionnaire, Noticing and Not-Worrying, were primarily related with Pos. Refl. Emo. The correlation index for the Noticing scale and for Pos. Refl. Emo was minus, whereas the correlation index for the second scale, Not-Worrying, obtained a positive sign. All standardised canonical coefficients were reported in Figure 1.

--- Figure 1 ---

\subsection{Relationship between all types of emotions, negative beliefs about health and the body and the MAIA scales}

The relationships between the study variables were analysed with the use of path analysis based on the maximum likelihood method. The preliminary model is depicted in Figure 2. --- Figure 2 ---

The preliminary model differed significantly from the data that was analysed, $\chi^{2}(13)=$ 87.06, $p<0.001$. The values of fit indices were NFI $=0.91$; CFI $=0.92, R M S E A=0.14$. In order to improve the fit of the model, statistically insignificant paths were removed, and statistically significant paths were added. The addition of paths was based on the values of modification indices with a threshold value of 4 . The path that was statistically insignificant was the path 
500 between Attention Regulation and Emo. Pos. Refl., $B=0.12, p>0.05$. The only directional 501 relationship involving Attention Regulation was the path between Attention Regulation and Emo.

502 Pos. Refl. Therefore, Attention Regulation was excluded from the model. In the next three 503 consecutive steps correlations between Emo. Neg. Aut. and Emo. Pos. Aut., between Emo. Neg. 504 Refl. and Emo. Pos. Aut. and a path between Trusting and Emo. Pos. Refl. were added. After 505 these four modifications the final model depicted in Figure 3 did not differ significantly from the 506 data that was analysed, $\chi^{2}(6)=9.70, p>0.05$. The values of fit indices were NFI $=0.99 ; C F I=$ 507 0.99, RMSEA $=0.05$.

508

Self-Regulation, Trusting and Not-Worrying were negatively related to Emo. Neg. Aut. and Emo. Neg. Refl. Negative beliefs were related to Emo. Neg. Aut. and Emo. Neg. Refl. positively. Self-Regulation and Trusting were positively related to Emo. Pos. Aut. and Emo. Pos. Refl. Negative beliefs were related to Emo. Pos. Aut. negatively. The final model explained 7.8\% of Emo. Pos. Refl. Variance, 15.2\% of Emo. Pos. Aut. variance, 25.8\% of Emo. Neg. Refl. variance and $24.5 \%$ of Emo. Neg. Aut variance.

\section{Discussion}

\subsection{The relationship between different types of emotions and interoceptive awareness}

The current study showed that there is a multivariate shared association between two sets of variables: MAIA components and different types of emotions: Neg. Aut. Emo., Neg. Refl. Emo, Pos. Aut. Emo., Pos. Refl. Emo. The model explained 41\% of the shared variance between two sets of variables. Scales such as: Noticing, Not-Worrying, Self-Regulation, Trusting were primarily associated with emotions. The canonical correlation analysis delivered interesting data illustrating a multivariate association between automatic and reflective emotions and interoceptive awareness. The first function, explaining the majority of the common variance, indicated a strong relationship between the Self-Regulation and Trusting scales and emotions with the increase of those dimensions in the function, the decrease of negative automatic and negative reflective emotions occurs, whereas positive automatic emotions escalate. An interesting pattern of relation between MAIA and emotions was investigated through the second function in canonical correlation analysis - there is an association between Noticing, Not-Worrying and positive reflective emotions. The increase of Noticing leads to an increase of positive reflective 
542 emotions, whereas an increase of Not-Worrying was associated with the opposite observation.

543 The Noticing scale reflects the subject's ability to detect inner body symptoms without

544 psychological appraisal and integration; it refers to the elementary aspect of interoception (Quadt

545 et al., 2018). The Not-Worrying scale contains statements expressing that the individual does not

546 react with worry or upset on pain or discomfort. Only one statement refers directly to the ability

547 to notice the sensations without concerns. Therefore, juxtaposing both scales, one can get the

548 impression that some of them may express slightly opposite tendencies. However, the second

549 function explains the minor part of the variance, therefore this result should rather be treated with 550 caution.

\subsection{The structure of associations between all types of emotions, negative beliefs about health and the body and MAIA scales}

The model illustrating the multiple distinct associations between negative beliefs, MAIA components and four types of emotions: Neg. Aut. Emo., Neg Refl. Emo., Pos. Aut. Emo., Pos. Refl. Emo. revealed a good adjustment to data and brought some new insight.

\subsubsection{Non-directional relationships between the variables that have been tested}

There is a relationship between Not-Worrying and Trusting which seems to be consistent with the theory, as both scales refer to an accepting, fearless, reliant attitude towards inner body sensations. On the other hand, both scales are not explicitly intertwined in the factorial structure of the MAIA questionnaire (Hanley et al., 2017; W. E. Mehling et al., 2018). Moreover, the relationship is weak. Interestingly, there is also a moderately strong relationship between the negative beliefs and Not-Worrying scales. Considering the content of both factors, it can be inferred that both components are theoretically opposite, as the Not-Worrying scale enables evaluation of attentional and emotional response to perceived bodily signals (Hanley et al., 2017), whereas the negative beliefs scale reflects a negative appraisal on the body. Another nondirectional relationship was observed between all types of emotions. We recognised a strong relationship between negative automatic and negative reflective emotions, a moderate relationship between positive automatic and positive reflective emotions, and a moderate negative relationship between negative automatic emotions and positive automatic emotions. Finally, there was a low negative relationship between negative reflective emotions and positive automatic emotions. The results obtained can be interpreted in the context of the dimensions of emotions. The division by origin seems to be more efficient in terms of positive emotions than with to negative. The split based on valence is more compelling than the distinction based on origin.

\subsubsection{The role of negative beliefs about health and body in explaining of the intensity of emotions}

Firstly, the model demonstrated a meaningful role of negative beliefs. There is an association between negative beliefs about health and the body and all types of declared emotions apart from Pos. Refl. Emo. Negative beliefs significantly predict the intensity of reported emotions - they 
584 are the strongest predictor for Neg. Aut. Emo. and Neg. Refl. Emo. Beliefs about being in danger 585 and evaluation of one's body as weak seem to play a crucial role in the reported emotional state, 586 especially in the framework of the COVID-19 pandemic. This result can be interpreted in the 587 context of a cognitive-behavioural approach. For instance, in hypochondriasis, biases in thinking, 588 such as negative automatic thoughts - instead of realistic, adaptive beliefs - influence affective 589 reaction (see e.g. Calvo \& Castillo, 2001; Marcus, Gurley, Marchi, \& Bauer, 2007; Williams, 590 2004). Applying this view to current findings suggests that even an individual who does not 591 suffer from an anxiety disorder, might experience increasing fear for their health in such an

592 593 unpredictable situation as a pandemic, partly due to undermining, fearful beliefs.

\subsubsection{The role of MAIA components in explaining intensity of emotions}

The path analysis revealed that scales such as Self-Regulation and Trusting predict all types of emotions. The Not-Worrying scale predicts only negative emotions.

The findings described indicate a crucial role of scales such as Self-Regulation, Trusting and Not-Worrying in the processes regulating the emotion, understood as minimising negative affect, which indirectly confirms the regulatory role of interoceptive awareness. The result remains consistent with the current state of knowledge, several studies have demonstrated that higher interoceptive awareness promotes affect downregulation through reappraisal, which is reflected in neural activity (Füstös et al., 2012). Moreover, individuals who are more aware of inner bodily sensations demonstrated more antecedent-focused and response-focused strategies for regulating emotion, such as supportive reappraisal or maladaptive suppression (Kever et al., 2015). Similar results were obtained in the game-playing context, where it was observed that greater interoceptive awareness was related to regulation strategies for emotions relating to health such as attempting a resolution of a negative state or seeking social support (Lobel et al., 2014).

The observed mechanism might be understood in the context of interoceptive awareness's relation with psychological well-being (see Hanley et al., 2017). Interoceptive awareness, together with dispositional mindfulness, predicts psychological well-being. It seems that enhancing the accepting body-mind relationship might deliver a more positive affect, especially in the case of automatic homeostatic emotions. However, more empirical data is required to verify this relation.

\subsubsection{Summary of the model structure}

For Neg. Aut. Emo and Neg. Refl. Emo we observed the same structure of predictors. The structure of predictors for negative and positive emotions shows moderate differences. Therefore, the following conclusions can be drawn: (1) the valence dimension (positive vs. negative) differentiates the structure of explanatory models; in other words, different factors predict the intensity of positive emotions and of negative emotions; (2) the origin dimension differentiates the structure of predictors slightly and refers to the presence of negative beliefs.

The model explained the variance of negative emotions, both reflective (25.85\%) and automatic (24.5\%), to a greater extent than positive (15.2\% of Emo. Pos. Aut. variance and 7.8\% of Emo. Pos. Refl. variance). The above results indicate that the influence of factors related to 
625 experiencing and assessing one's own body occurs within the reduction of negative affect rather 626 than the enhancement of positive affect.

627

628

629

630

631

632

633

634

635

636

637

638

639

640

641

642

\subsection{Limitations}

This study has its limitations. The data were collected from users of Facebook groups. In the sample, most participants were inhabitants of large cities and persons with higher education and which, therefore, constrained the representativeness of the sample. For that reason, the results may be a specific to the population, presenting relatively high levels of interoceptive awareness. Further studies on the general population are needed. The sample size can also be considered as a study limitation, especially when data is collected via the Internet. Due to specific time-related restrictions regarding movement, the only way to collect data was to conduct an online survey. This method excludes the use of objective measures of interoception, such as heartbeat tracking tasks, which in turn could deliver interesting information.

To understand more profoundly the character of the relationship between one's bodily experience, negative beliefs about health and the body and emotional responses to threatening events, it seems useful to apply additional self-reported measurements, such as dispositional mindfulness, emotion regulation strategies and coping styles. In the study, only two dimensions of emotions were operationalised. The dimension of arousal was not included in the design due to the aim of the study (the purpose was to verify the relationship between the body related variable and the emotions based on variation in the valence and arousal dimensions). This direction of research seems to be interesting, as there is some evidence that highly interoceptively aware individuals perceive stimuli as more arousing (Barrett et al., 2004; Dunn et al., 2010). Moreover, there are varied approaches to emotions (e.g.: Moors et al., 2019); possibly applying another theoretical framework could result in a new direction of research.

\section{Conclusions}

The study has revealed that both interoceptive awareness and negative beliefs about health and the body significantly explain the variance in emotional responses reported during the COVID-19 pandemic. Scales such as Self-Regulation and Trusting are predictors for the types of emotions that were tested. This result highlights the regulative role of interoceptive awareness. The trustful attitude towards the body and its capacity for regulating distress by directing attention to body sensations enables an improvement of individual well-being through diminishing the experiencing of negative emotions and enhancing the experiencing of positive ones. At the same time, Not-Worrying is only a valid predictor for negative emotions. However, in the case of negative emotions, it was negative beliefs about health and the body that turned out to be the strongest predictor. The emotion typology applied - based on the dimensions of valence and origin - brings about a wider understanding of the nature of emotional responses in general.

\section{Acknowledgements}

This work was supported by the University of Warsaw in the program "Initiative of Excellence Research University" (IDUB), from funds awarded by the Ministry of Science and Higher 
666 Education in the form of a subsidy for the maintenance and development of research potential in 667 years $2020-2026$.

668

\section{References}

Barrett, L. F. (1998). Discrete Emotions or Dimensions? The Role of Valence Focus and Arousal Focus. Cognition and Emotion, 12(4), 579-599. https://doi.org/10.1080/026999398379574

Barrett, L. F., Bliss-Moreau, E., Quigley, K. S., \& Aronson, K. R. (2004). Interoceptive sensitivity and self-reports of emotional experience. Journal of Personality and Social Psychology, 87(5), 684-697. https://doi.org/10.1037/0022-3514.87.5.684

Bornemann, B., \& Singer, T. (2017). Taking time to feel our body: Steady increases in heartbeat perception accuracy and decreases in alexithymia over 9 months of contemplative mental training. Psychophysiology, 54(3), 469-482. https://doi.org/10.1111/psyp.12790

Calì, G., Ambrosini, E., Picconi, L., Mehling, W. E., \& Committeri, G. (2015a). Investigating the relationship between interoceptive accuracy, interoceptive awareness, and emotional susceptibility. Frontiers in Psychology, 6, 1202. https://doi.org/10.3389/fpsyg.2015.01202

Calì, G., Ambrosini, E., Picconi, L., Mehling, W. E., \& Committeri, G. (2015b). Investigating the relationship between interoceptive accuracy, interoceptive awareness, and emotional susceptibility. Frontiers in Psychology, 6, 1202. https://doi.org/10.3389/fpsyg.2015.01202

Calvo, M. G., \& Dolores Castillo, M. (2001). Selective interpretation in anxiety: Uncertainty for threatening events. Cognition and Emotion, 15(3), 299-320. https://doi.org/10.1080/02699930126040

Cameron, O. G. (2001). Interoception: The inside story - A model for psychosomatic processes. Psychosomatic Medicine, 63(5), 697-710. https://doi.org/10.1097/00006842-20010900000001

Carruthers, G. (2008). Types of body representation and the sense of embodiment. Consciousness and Cognition, 17(4), 1302-1316. https://doi.org/10.1016/j.concog.2008.02.001

Cioffi, D. (1991a). Beyond attentional strategies: A cognitive-perceptual model of somatic interpretation. Psychological Bulletin, 109(1), 25-41. https://doi.org/10.1037/00332909.109.1.25

Cioffi, D. (1991b). Beyond attentional strategies: A cognitive-perceptual model of somatic interpretation. Psychological Bulletin, 109(1), 25-41. https://doi.org/10.1037/00332909.109.1.25

Clore, G. L., \& Ortony, A. (2010). Appraisal theories: How cognition shapes affect in emotion. In M. Lewis, J. M. Haviland-Jones, \& L. F. Barrett (Eds.), Handbook of emotions (3rd ed., pp. 628-644). The Guilford Press.

Cullen, W., Gulati, G., \& Kelly, B. D. (2020). Mental health in the COVID-19 pandemi. QJM: An International Journal of Medicine, 113, 311-312.

Damasio, A. R. (1998). Emotion in the perspective of an integrated nervous system. In Brain Research Reviews (Vol. 26).

Damasio, A. R., Grabowski, T. J., Bechara, A., Damasio, H., Ponto, L. L. B., Parvizi, J., \& Hichwa, R. D. (2000). Subcortical and cortical brain activity during the feeling of selfgenerated emotions. Nature Neuroscience, 3(10), 1049-1056. https://doi.org/10.1038/79871

Damasio, A. (2010). Self comes to mind: constructing the conscious mind. Pantheon.

Damasio, A. R. (1994). Descartes' error: Emotion, reason and the human brain. Grosset/Putnam.

Dickerson, S. S., \& Kemeny, M. E. (2004). Acute Stressors and Cortisol Responses: A Theoretical Integration and Synthesis of Laboratory Research. https://doi.org/10.1037/0033- 
714

715

716

717

718

719

720

721

722

723

724

725

726

727

728

729

730

731

732

733

734

735

736

737

738

739

740

741

742

743

744

745

746

747

748

749

750

751

752

753

754

755

756

757

758

759

760

761

762

2909.130.3.355

Dienstbier, R. A. (1989). Arousal and Physiological Toughness: Implications for Mental and Physical Health. Psychological Review, 96(1), 84-100. https://doi.org/10.1037/0033295X.96.1.84

Dunn, B. D., Galton, H. C., Morgan, R., Evans, D., Oliver, C., Meyer, M., Cusack, R., Lawrence, A. D., \& Dalgleish, T. (2010). Listening to your heart: How interoception shapes emotion experience and intuitive decision making. Psychological Science, 21(12), 1835-1844. https://doi.org/10.1177/0956797610389191

Ellis, A. (1991). The revised ABC's of rational-emotive therapy (RET). Journal of RationalEmotive and Cognitive-Behavior Therapy 1991 9:3, 9(3), 139-172. https://doi.org/10.1007/ BF01061227Ernst, J., Northoff, G., Böker, H., Seifritz, E., \& Grimm, S. (2013). Interoceptive awareness enhances neural activity during empathy. Human Brain Mapping, 34(7), 1615-1624. https://doi.org/10.1002/hbm.22014

Farb, N., Daubenmier, J., Price, C. J., Gard, T., Kerr, C., Dunn, B. D., Klein, A. C., Paulus, M. P., \& Mehling, W. E. (2015). Interoception, contemplative practice, and health. Frontiers in Psychology, 6(JUN). https://doi.org/10.3389/fpsyg.2015.00763

Fogel, A. (2009). The Norton series on interpersonal neurobiology. The psychophysiology of selfawareness: Rediscovering the lost art of body sense. W W Norton \& Co.

Folkman, S., \& Lazarus, R. S. (1985). If it changes it must be a process: Study of emotion and coping during three stages of a college examination. Journal of Personality and Social Psychology, 48(1), 150-170.

Frijda, N. (2007). The laws of emotion. Erlbaum.

Füstös, J., Gramann, K., Herbert, B. M., \& Pollatos, O. (2012). On the embodiment of emotion regulation: interoceptive awareness facilitates reappraisal. Social Cognitive and Affective Neuroscience, 8(8), 911-917.

Hanley, A. W., Mehling, W. E., \& Garland, E. L. (2017). Holding the body in mind: Interoceptive awareness, dispositional mindfulness and psychological well-being. Journal of Psychosomatic Research, 99, 13-20. https://doi.org/10.1016/j.jpsychores.2017.05.014

Harrison, J. A., Mullen, P. D., \& Green, L. W. (1992). A meta-analysis of studies of the Health Belief Model with adults. Health Education Research, 7(1), 107-116.

Hochbaum, G. (1985). Public Participation in Medical Screening Programs: A Sociopsychological Study. Public Health Service Publication.

Hölzel, B. K., Lazar, S. W., Gard, T., Schuman-Olivier, Z., Vago, D. R., \& Ott, U. (2011). How does mindfulness meditation work? Proposing mechanisms of action from a conceptual and neural perspective. Perspectives on Psychological Science (Vol. 6, Issue 6, pp. 537-559). https://doi.org/10.1177/1745691611419671

Imbir, K. K. (2016). From heart to mind and back again. A duality of emotion overview on emotion-cognition interactions. New Ideas in Psychology, 43, 39-49. https://doi.org/10.1016/J.NEWIDEAPSYCH.2016.04.001

Iodice, P., Porciello, G., Bufalari, I., Barca, L., \& Pezzulo, G. (2019). An interoceptive illusion of effort induced by false heart-rate feedback. Proceedings of the National Academy of Sciences of the United States of America, 116(28), 13897-13902. https://doi.org/10.1073/pnas.1821032116

Jarymowicz, M. (2012). Understanding Human Emotions. Journal of Russian and East European Psychology, 50(3), 9-25. https://doi.org/10.2753/RPO1061-0405500301

Jarymowicz, M. T., \& Imbir, K. K. (2015). Toward a Human Emotions Taxonomy (Based on Their Automatic vs. Reflective Origin). Emotion Review, 7(2), 183-188. https://doi.org/10.1177/1754073914555923

Kendler, K. S., Karkowski, L. M., \& Prescott, C. A. (1998). Stressful Life Events and Major

Peer] reviewing PDF | (2020:12:56452:3:0:NEW 3 Nov 2021) 
Depression: Risk Period, Long-Term Contextual Threat, and Diagnostic Specificity. The Journal of Nervous \& Mental Disease, 186(11), 661-669.

Kessler, R. C. (1997). The Effects Of Stressful Life Events On Depression. Annual Review of Psychology, 48(1), 191-214. https://doi.org/10.1146/annurev.psych.48.1.191

Kever, A., Pollatos, O., Vermeulen, N., \& Grynberg, D. (2015). Interoceptive sensitivity facilitates both antecedent- and response-focused emotion regulation strategies. Personality and Individual Differences, 87, 20-23. https://doi.org/10.1016/j.paid.2015.07.014

Lazarus, R. S. (1991). Cognition and motivation in emotion. American Psychologist, 46(4), 352367. https://doi.org/10.1037/0003-066X.46.4.352

Lobel, A., Granic, I., \& Engels, R. C. M. E. (2014). Stressful Gaming, Interoceptive Awareness, and Emotion Regulation Tendencies: A Novel Approach. Cyberpsychology, Behavior, and Social Networking, 17(4), 222-227. https://doi.org/10.1089/cyber.2013.0296

Marcus, D. K., Gurley, J. R., Marchi, M. M., \& Bauer, C. (2007). Cognitive and perceptual variables in hypochondriasis and health anxiety: A systematic review. Clinical Psychology Review, 27(2), 127-139. https://doi.org/10.1016/j.cpr.2006.09.003

Mazure, C. M. (1998). Life stressors as risk factors in depression. Clinical Psychology: Science and Practice, 5(3), 291-313. https://doi.org/10.1111/j.1468-2850.1998.tb00151.x

Mehling, W. (2016). Differentiating attention styles and regulatory aspects of self-reported interoceptive sensibility. In Philosophical Transactions of the Royal Society B: Biological Sciences (Vol. 371, Issue 1708). Royal Society of London. https://doi.org/10.1098/rstb.2016.0013

Mehling, W. E., Acree, M., Stewart, A., Silas, J., \& Jones, A. (2018). The multidimensional assessment of interoceptive awareness, version 2 (MAIA-2). PLoS ONE, 13(12). https://doi.org/10.1371/journal.pone.0208034

Mehling, W. E., Daubenmier, J., Price, C. J., Acree, M., Bartmess, E., \& Stewart, A. L. (2013). Self-reported interoceptive awareness in primary care patients with past or current low back pain. Journal of Pain Research, 6, 403-418. https://doi.org/10.2147/JPR.S42418

Mehling, W. E., Gopisetty, V., Daubenmier, J., Price, C. J., Hecht, F. M., \& Stewart, A. (2009). Body awareness: Construct and self-report measures. PLoS ONE, 4(5), e5614. https://doi.org/10.1371/journal.pone.0005614

Mehling, W. E., Price, C., Daubenmier, J. J., Acree, M., Bartmess, E., \& Stewart, A. (2012a). The Multidimensional Assessment of Interoceptive Awareness (MAIA). PLoS ONE, 7(11), e48230-e48230. https://doi.org/10.1371/journal.pone.0048230

Mehling, W. E., Wrubel, J., Daubenmier, J. J., Price, C. J., Kerr, C. E., Silow, T., Gopisetty, V., \& Stewart, A. L. (2011). Body Awareness: A phenomenological inquiry into the common ground of mind-body therapies. Philosophy, Ethics, and Humanities in Medicine, 6(1). https://doi.org/10.1186/1747-5341-6-6

Monroe, Scott M.Hadjiyannakis, K. (2002). The social environment and depression: Focusing on severe life stress. In I. H. Gotlib \& C. Hammen (Eds.), Handbook of depression (2nd ed., pp. 314-340). The Guilford Press.

Montoya, P., Schandry, R., \& Miiller, A. (1993). Heartbeat evoked potentials (HEP 
812

813

814

815

816

817

818

819

820

821

822

823

824

825

826

827

828

829

830

831

832

833

834

835

836

837

838

839

840

841

842

843

844

845

846

847

848

849

850

851

852

853

854

855

856

857

858

859

860
Moors, A., Ellsworth, P. C., Scherer, K. R., \& Frijda, N. H. (2013). Appraisal theories of emotion: State of the art and future development. Emotion Review, 5(2), 119-124. https://doi.org/10.1177/1754073912468165

Moors, A., Fini, C., Everaert, T., Bardi, L., Bossuyt, E., Kuppens, P., \& Brass, M. (2019). The role of stimulus-driven versus goaldirected processes in fight and flight tendencies measured with motor evoked potentials induced by Transcranial Magnetic Stimulation. PLoS ONE, 14(5), e0217266. https://doi.org/10.1371/journal.pone.0217266

Moors, A., \& Fischer, M. (2019). Demystifying the role of emotion in behaviour: toward a goaldirected account. Cognition and Emotion, 33(1), 94-100. https://doi.org/10.1080/02699931.2018.1510381

Paykel, E. S. (2003). Life events and affective disorders. Acta Psychiatrica Scandinavica, Supplement, 108(418), 61-66. https://doi.org/10.1034/j.1600-0447.108.s418.13.x

Perrin, P. C. (2009). Preparing for an influenza pandemic: Mental health considerations. Prehospital and Disaster Medicine, 24(3), 223-230.https://doi.org/10.1017/S1049023X00006853

Person, B., Sy, F., Holton, K., Govert, B., Liang, A., Garza, B., Gould, D., Hickson, M., McDonald, M., Mejer, C., Smith, J., Veto, L., Williams, W., \& Zauderer, L. (2004). Fear and Stigma: The Epidemic within the SARS Outbreak. In Emerging Infectious Diseases (Vol. 10, Issue 2, pp. 358-363). Centers for Disease Control and Prevention (CDC). https://doi.org/10.3201/eid1002.030750

Pezzulo, G., Maisto, D., Barca, L., \& Van den Bergh, O. (2019). Symptom Perception From a Predictive Processing Perspective. Clinical Psychology in Europe, 1(4), 1-14. https://doi.org/10.32872/cpe.v1i4.35952

Pollatos, O., Gramann, K., \& Schandry, R. (2007). Neural systems connecting interoceptive awareness and feelings. Human Brain Mapping, 28(1), 9-18. https://doi.org/10.1002/hbm.20258

Pollatos, O., Kirsch, W., \& Schandry, R. (2005). On the relationship between interoceptive awareness, emotional experience, and brain processes. Cognitive Brain Research, 25(3), 948-962. https://doi.org/10.1016/j.cogbrainres.2005.09.019

Pollatos, O., \& Schandry, R. (2008). Emotional processing and emotional memory are modulated by interoceptive awareness. Cognition and Emotion, 22(2), 272-287. https://doi.org/10.1080/02699930701357535

Price, C. J., \& Hooven, C. (2018). Interoceptive Awareness Skills for Emotion Regulation: Theory and Approach of Mindful Awareness in Body-Oriented Therapy (MABT). Frontiers in Psychology, 9(May), 798. https://doi.org/10.3389/fpsyg.2018.00798

Quadt, L., Critchley, H. D., \& Garfinkel, S. N. (2018). The neurobiology of interoception in health and disease. Annals of the New York Academy of Sciences, 1428(1), 112-128. https:// doi.org/10.1111/nyas.13915

Reykowski, J. (1989). Dimensions of development of moral values. In N. Eisenberg, J. Reykowski, \& E. Staub (Eds.), Social and Moral Values (pp. 23-44). Erlbaum.

Rosenstock, I. M. (1966). Why people use health services. The Milbank Memorial Fund Quarterly, 44(3). https://doi.org/10.2307/3348967

Rosenstock, I. M. (1960). What research in motivation suggests for public health. American Journal of Public Health, 50, 295-302. https://doi.org/10.2105/AJPH.50.3_Pt_1.295

Rosenstock, I. M., Strecher, V. J., \& Becker, M. H. (1988). Social Learning Theory and the Health Belief Model. Health Education \& Behavior, 15(2), 175-183.

https://doi.org/10.1177/109019818801500203

Rosenstock, I. M., Strecher, V. J., \& Becker, M. H. (1994). The Health Belief Model and HIV Risk Behavior Change (pp. 5-24). Springer. https://doi.org/10.1007/978-1-4899-1193-3_2 
861

862

863

864

865

866

867

868

869

870

871

872

873

874

875

876

877

878

879

880

881

882

883

884

885

886

887

888

889

890

891

892

893

894

895

896

897

898

899

900
Schachter, S., \& Singer, J. (1962). Cognitive, social, and physiological determinants of emotional state. Psychological Review, 69(5), 379-399. https://doi.org/10.1037/h0046234

Schwarzer, R. (1994). Optimism, vulnerability, and self-beliefs as health-related cognitions: A systematic overview. Psychology \& Health, 9(3), 161-180. https://doi.org/10.1080/08870449408407475

Strack, F, \& Deutsch, R. (2014). The Reflective-impulsive Model. In W. Sherman, B. Gawronski \& Y. Trope (Eds.), Dual-Process Theories of the Social Mind (pp. 92-104). Guilford Press.

Strack, Fritz, \& Deutsch, R. (2004). Reflective and impulsive determinants of social behavior. Personality and Social Psychology Review, 8(3), 220-247. https://doi.org/10.1207/s15327957pspr0803_1

Tang, Y. Y., Hölzel, B. K., \& Posner, M. I. (2015). The neuroscience of mindfulness meditation. In Nature Reviews Neuroscience (Vol. 16, Issue 4, pp. 213-225). Nature Publishing Group. https://doi.org/10.1038/nrn3916

Tomaka, J., Blascovich, J., Kelsey, R. M., \& Leitten, C. L. (1993). Subjective, Physiological, and Behavioral Effects of Threat and Challenge Appraisal. Journal of Personality and Social Psychology, 65(2), 248-260. https://doi.org/10.1037/0022-3514.65.2.248

Tsakiris, M., \& Critchley, H. (2016). Interoception beyond homeostasis: affect, cognition and mental health. Philosophical Transactions of the Royal Society B: Biological Sciences, 371(1708), 20160002. https://doi.org/10.1098/rstb.2016.0002

Tsuruta, K., Fujii, Y., Maeda, H., Murakata, T., \& Kato, T. (2005). Mental health status and effects on daily life of patients of a large outbreak of Legionnaires Disease. [Nippon Kōshū Eisei Zasshi] Japanese Journal of Public Health, 52(4), 308-318. https://doi.org/10.11236/jph.52.4_308

Wiens, S., Mezzacappa, E. S., \& Katkin, E. S. (2000). Heartbeat detection and the experience of emotions. Cognition and Emotion, 14(3), 417-427. https://doi.org/10.1080/026999300378905

Williams, P. G. (2004). The Psychopathology of Self-Assessed Health:A Cognitive Approach to Health Anxiety and Hypochondriasis. Cognitive Therapy and Research. https://doi.org/10.1023/B:COTR.0000045569.25096.44

Wu, K. K., Chan, S. K., \& Ma, T. M. (2005). Posttraumatic stress, anxiety, and depression in survivors of severe acute respiratory syndrome (SARS). Journal of Traumatic Stress, 18(1), 39-42. https://doi.org/10.1002/jts.20004

Zajonc, R. B. (1980). Feeling and thinking: Preferences need no inferences. American Psychologist, 35(2), 151-175. https://doi.org/10.1037/0003-066X.35.2.151

Zaki, J., Davis, J. I., \& Ochsner, K. N. (2012). Overlapping activity in anterior insula during interoception and emotional experience. NeuroImage, 62(1), 493-499.

https://doi.org/10.1016/j.neuroimage.2012.05.012 


\section{Figure 1}

Standardized canonical coefficients for the first and second functions.

Each box contains the standardized canonical coefficients for the variable in the first function on the top, and for the second function on the bottom. The first function is represented by a solid line, and the second function is represented by dashed lines. Shared variance among interoceptive awareness and automatic and reflective emotions across all functions is described with R2. Squared canonical correlations representing shared variance between MAIA's scales and automatic and reflective emotions are described with Rc2 for each function.

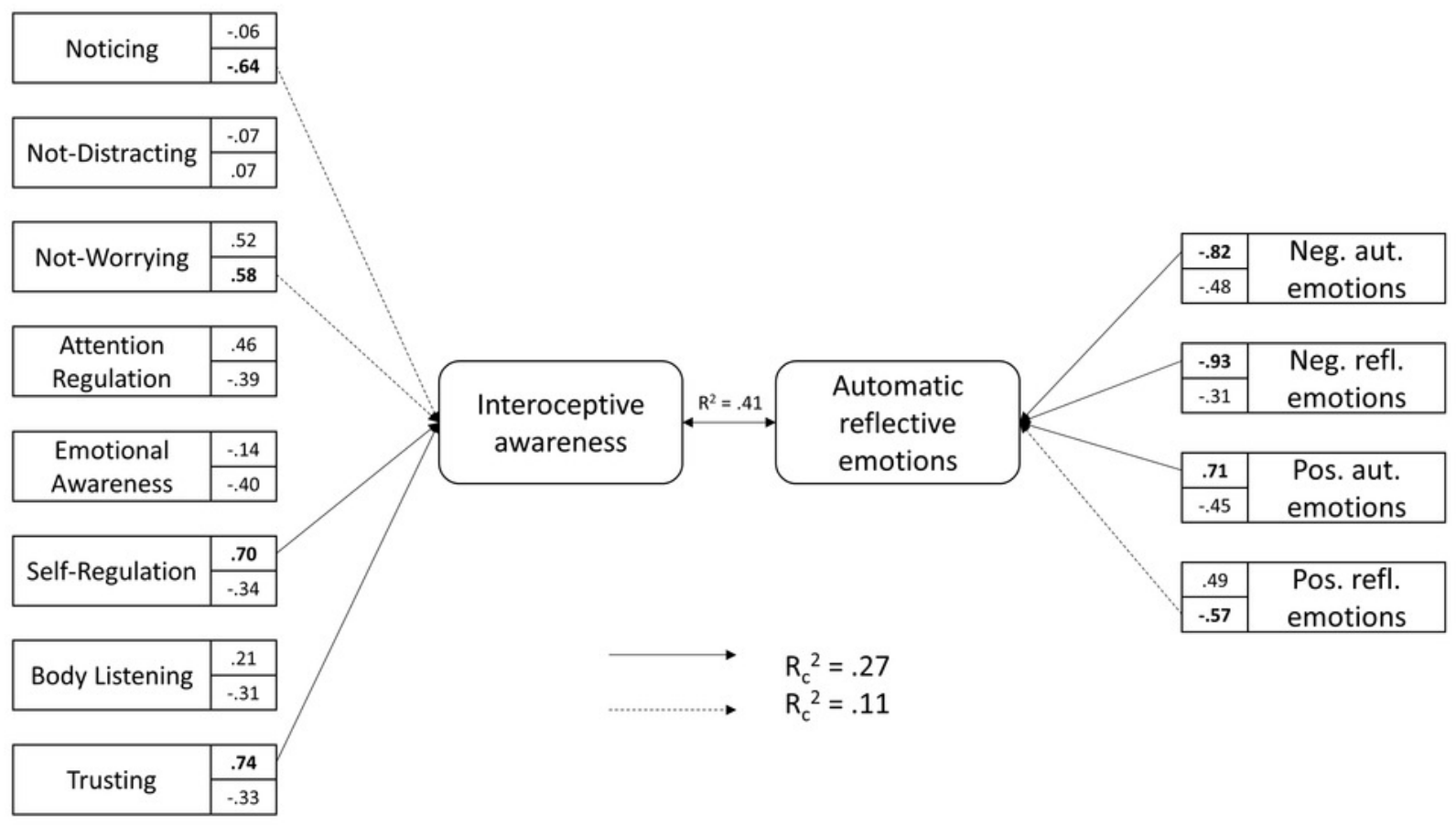


Figure 2

The preliminary model of relationships between different types of emotions, MATA's scales and negative beliefs about health and body.

The preliminary model differed significantly from the analysed data, $c^{2}(13)=87.06, p<.001$. The values of fit indices were equal to $N F I=.91 ; C F I=.92, R M S E A=.14$.

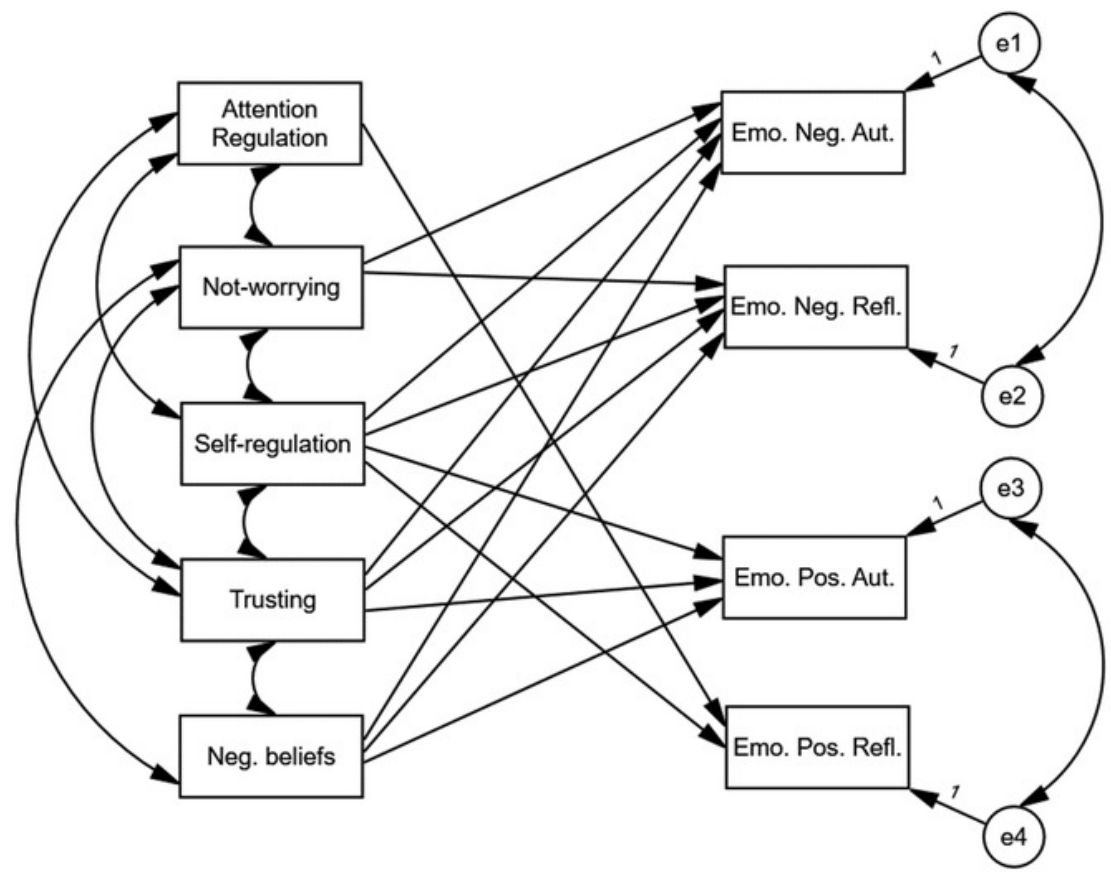


Figure 3

Final model of relationships between different types of emotions, MAIA's scales and negative beliefs about health and body.

The final model depicted did not differ significantly from the analysed data, $\chi^{2}(6)=9.70$, $p>.05$. The values of fit indices were equal to $N F I=.99 ; C F I=.99, R M S E A=.05$.

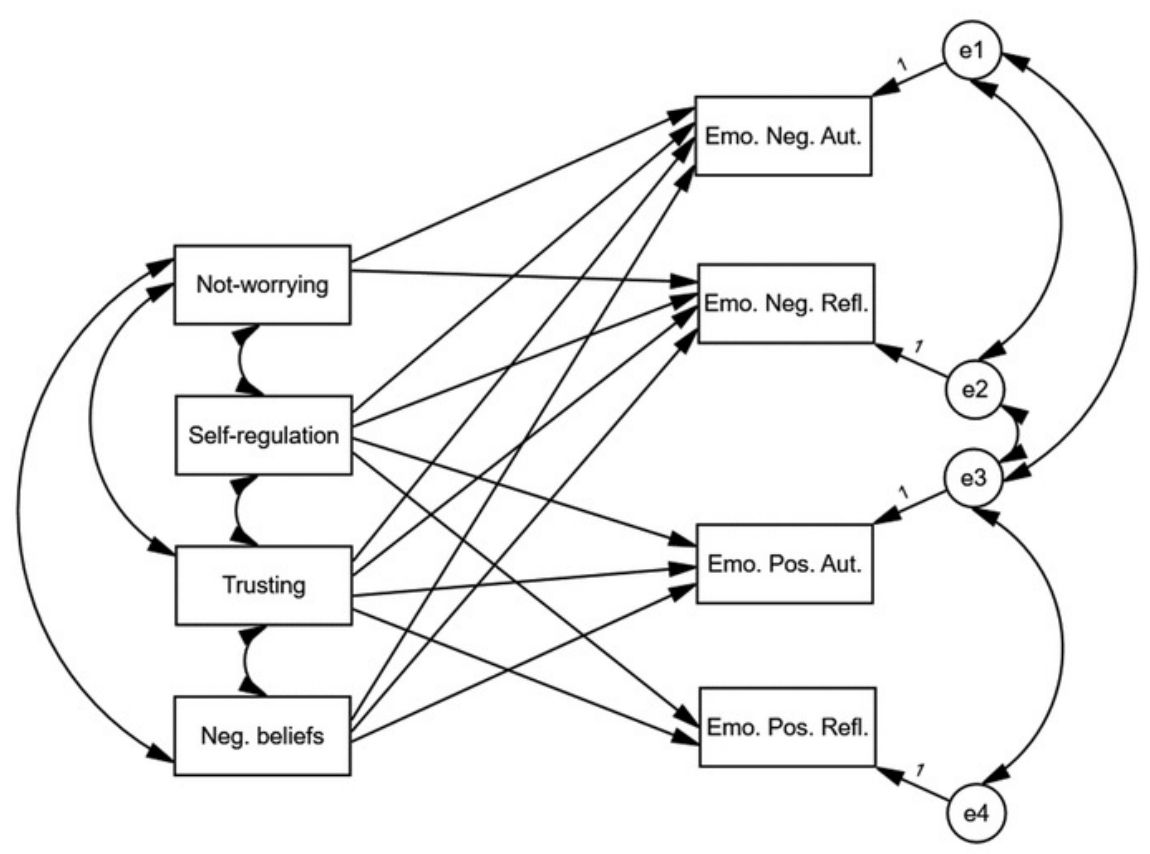




\section{Table 1 (on next page)}

Emotion typology

The table presents the typology of emotions based on valence and origin. 


\section{Table 1}

2 Emotion typology.

\begin{tabular}{ll|ll} 
Negative emotions & & Positive emotions & \\
\hline Automatic & Reflective & Automatic & Reflective \\
\hline Suffering & Shame & Alleviation & Persistence \\
Helplessness & Sadness & Reassurance & Compassion \\
Frustration & Dejection & Excitation & Hope \\
Breakdown & Depression & Relaxation & Courage \\
Terror & Envy & Tenderness & Loyalty
\end{tabular}




\section{Table 2 (on next page)}

Means, standard deviations and internal consistencies.

Means, standard deviations and internal consistencies for: emotions based on valence and origin emotion categories, MAIA scales, negative beliefs about health and body. For MAIA's scales, the results were compared with the reliability obtained in Mehling and colleagues' research (Mehling et al., 2012), values are shown below in italics. 
1 Table 2

2 Means, standard deviations and internal consistencies for: emotions based on valence and origin

3 emotion categories, MAIA scales, negative beliefs about health and body.

4 For MAIA's scales, the results were compared with the reliability obtained in Mehling and

5 colleagues' research (Mehling et al., 2012), values are shown below in italics.

6

\begin{tabular}{|c|c|c|c|}
\hline & MEAN & $\mathrm{SD}$ & $\alpha$ \\
\hline Negative automatic emotions & $\mathrm{M}=3.53$ & $\mathrm{SD}=1.52$ & .85 \\
\hline Negative reflective emotions & $\mathrm{M}=2.91$ & $\mathrm{SD}=1.25$ & .77 \\
\hline Positive automatic emotions & $\mathrm{M}=3.01$ & $\mathrm{SD}=1.20$ & .74 \\
\hline Positive reflective emotions & $M=4.16$ & $\mathrm{SD}=1.12$ & .65 \\
\hline Noticing & $\mathrm{M}=4.43$ & $\mathrm{SD}=1.03$ & $.69 ; .69$ \\
\hline Not Distracting & $\mathrm{M}=3.34$ & $\mathrm{SD}=1.05$ & $.59 ; .66$ \\
\hline Not-Worrying & $\mathrm{M}=3.12$ & $\mathrm{SD}=1.09$ & $.64 ; .67$ \\
\hline Attention Regulation & $\mathrm{M}=3.65$ & $\mathrm{SD}=.99$ & $.85 ; .87$ \\
\hline Emotional awareness & $\mathrm{M}=4.54$ & $\mathrm{SD}=1.11$ & $.84 ; .82$ \\
\hline Self-Regulation & $\mathrm{M}=3.21$ & $\mathrm{SD}=1.19$ & $.82 ; .83$ \\
\hline Body listening & $\mathrm{M}=3.35$ & $\mathrm{SD}=1.28$ & $.81 ; .82$ \\
\hline Trusting & $\mathrm{M}=3.89$ & $\mathrm{SD}=1.35$ & $.89 ; .79$ \\
\hline General beliefs about health and body & $M=2.58$ & $\mathrm{SD}=.72$ & .81 \\
\hline
\end{tabular}




\section{Table 3(on next page)}

Examples of negative beliefs about health and body used in the study. 
Table 3

2 Examples of negative beliefs about health and body used in the study.

Belief in English:

1. I believe that my health is in danger.

2. I believe that my life is in danger.

3. My immune system is not durable enough, to deal with the disease.

4. My body is weak.

5. I'm easily infected.

6. To detect potential symptoms as quickly as possible, you need to carefully monitor your body's functioning.

7. Even a small change in the functioning of my body can be a symptom of a developing disease.

8. I can't do anything to protect my body from getting sick.

9. My respiratory system is not as efficient as for other people's respiratory systems.

10. If I fall ill, my body will definitely not be able to handle it.
Polish translation:

Uważam, że moje zdrowie jest zagrożone.

Uważam, że moje życie jest zagrożone.

Mój układ odpornościowy nie jest wystarczajaco silny, aby poradzić sobie z choroba.

Moje ciało jest słabe.

Łatwo się zarażam.

Aby jak najszybciej wykryć potencjalne objawy, trzeba uważnie przygladać się funkcjonowaniu swojego organizmu.

Nawet niewielka zmiana $w$ funkcjonowaniu mojego organizmu może być symptomem rozwijajacej się choroby.

Nie jestem $w$ stanie nic zrobić, aby uchronić swój organizm przed zachorowaniem.

Mój układ oddechowy nie jest tak wydolny jak u innych osób.

Jeżeli zachoruje, mój organizm na pewno sobie z tym nie poradzi. 
Table 4 (on next page)

Factor loadings acquired in confirmatory factor analysis. 
$1 \quad$ Table 4

2 Factor loadings acquired in confirmatory factor analysis.

\begin{tabular}{lcc}
\hline Item no. & $f$ & $p$ \\
\hline 1 & .48 & .001 \\
2 & .49 & .001 \\
3 & .74 & .001 \\
4 & .76 & .001 \\
5 & .67 & .001 \\
6 & .28 & .001 \\
7 & .34 & .001 \\
8 & .30 & .001 \\
9 & .58 & .001 \\
10 & .47 & .001
\end{tabular}

$3 f$ - factor loadings; $p$ - statistical significance 
Table 5 (on next page)

Values of correlation coefficients in the model. 
1

2

Values of correlation coefficients.

\begin{tabular}{lllrc}
\hline Relationships & & & $r$ & $p$ \\
\hline Not-worrying & $<-->$ & Self-regulation & .15 & .008 \\
Self-regulation & $<-->$ & Trusting & .48 & .001 \\
Trusting & $<-->$ & Neg. beliefs & -.11 & .027 \\
Not-worrying & $<-->$ & Trusting & .15 & .011 \\
Not-worrying & $<-->$ & Neg. beliefs & -.32 & .001 \\
Emo. Neg. Aut. & $<-->$ & Emo. Neg. Refl. & .79 & .001 \\
Emo. Pos. Aut. & $<-->$ & Emo. Pos. Relf. & .37 & .001 \\
Emo. Neg. Aut. & $<-->$ & Emo. Pos. Aut. & -.41 & .001 \\
Emo. Neg. Refl. & $<-->$ & Emo. Pos. Aut. & -.29 & .001 \\
\hline$r-$ correlation coefficient; $p-$ statistical significance & &
\end{tabular}

4

5

Table 5 
Table 6(on next page)

Values of regression coefficients in the model. 
1

2

\begin{tabular}{lllcc}
\hline Relationships & & & $B$ & $p$ \\
\hline Emo. Neg. Aut. & $<---$ & Self-regulation & -.13 & .031 \\
Emo. Neg. Aut. & $<---$ & Trusting & -.12 & .032 \\
Emo. Neg. Aut. & $<---$ & Neg. beliefs & .34 & .001 \\
Emo. Neg. Aut. & $<---$ & Not-worrying & -.17 & .001 \\
Emo. Neg. Refl. & $<---$ & Not-worrying & -.16 & .002 \\
Emo. Neg. Refl. & $<---$ & Self-regulation & -.17 & .004 \\
Emo. Neg. Refl. & $<---$ & Trusting & -.16 & .005 \\
Emo. Neg. Refl. & $<---$ & Neg. beliefs & .31 & .001 \\
Emo. Pos. Aut. & $<---$ & Self-regulation & .19 & .002 \\
Emo. Pos. Aut. & $<---$ & Trusting & .22 & .001 \\
Emo. Pos. Aut. & $<---$ & Neg. beliefs & -.13 & .008 \\
Emo. Pos. Refl. & $<---$ & Trusting & .17 & .008 \\
Emo. Pos. Refl. & $<---$ & Self-regulation & .16 & .014 \\
\hline$B-$ regression coefficient; $p-$ statistical significance & &
\end{tabular}

